\title{
Imersão em games narrativos ${ }^{1}$
}

\author{
Suely Fragoso
}

Resumo: O texto discute as expressões utilizadas para caracterizar a experiência de imersão em games narrativos. O ponto de partida é uma revisão dos significados associados à suspensão de descrença na literatura, no cinema e na televisão, orientada pelo questionamento do mito da audiência ingênua, incapaz de distinguir entre a representação e a realidade. Duas características das narrativas midiáticas interativas - o exercício da agência e as disparidades entre as interfaces de hardware e software - evidenciam o caráter ativo do envolvimento do público com as representações midiáticas. Propõe-se que, no caso dos games, essa habilidade que permite agir simultaneamente no mundo do jogo e no mundo real estaria melhor caracterizada como uma encenação de crença.

Palavras-chave: games; imersão; suspensão de descrença; agência; interatividade; interfaces; encenação de crença.

Abstract: Immersion in narrative games - This paper discusses the expressions used to refer to the experience of immersive in narrative games. The starting point is a review of the meanings associated with the suspension of disbelief in literature, cinema and television, challenging the myth of the naïve audience that cannot distinguish between representation and reality. Two characteristics of interactive media narratives - the possibility of agency and the disparities between hardware and software interfaces - reveal the active nature of the audience's involvement with media representations. It is proposed that, in the case of games, this ability, which allows for simultaneous actions in the world of games and in the real world, is better described as a performance of belief.

Keywords: games; immersion; suspension of disbelief; agency; interactivity; interfaces; performance of belief.

\section{Introdução}

Este texto consiste em uma discussão teórica sobre a utilização da expressão suspensão de descrença para descrever a experiência de envolvimento com games,

1 Este trabalho foi produzido como parte de uma pesquisa apoiada pelo Conselho Nacional de Desenvolvimento Científico e Tecnológico (CNPq). Uma versão (ampliada) do texto foi apresentada durante a 22 a Compós (Salvador, 2013). A autora é grata aos colegas do GT Comunicação e Cibercultura, cujos comentários e sugestões foram importantes para a reelaboração do artigo. Rigorosamente, trata-se de uma contenda que marcou o estudo de games entre a última década dos anos 90 e a primeira desta século, tendo como figuras proeminentes, por exemplo, entre os narratólogos, Brenda Laurel e Janet Murray e, entre os ludólogos, Espen Aarseth e Jesper Juul. 
a partir de sua aplicação à literatura, teatro, cinema e televisão. A opção de adotar como ponto de partida uma ideia nascida na crítica literária poderia causar a impressão de que a proposta é alinhada com a corrente de estudo dos games identificada com a narratologia, à qual se opõem os defensores da ludologia. Atualmente, diz-se que a disputa entre ludólogos e narratólogos ${ }^{2}$ está superada, como deveria realmente estar - entretanto, em alguns círculos e situações, ela parece longe de ter sido resolvida. Para muitos seguidores da corrente ludológica, abordar os games tendo como ponto de partida um conceito nascido na literatura e segundo um roteiro constituído por meios narrativos e audiovisuais continua sendo uma heresia. E de fato o seria, caso a pretensão deste texto fosse meramente forçar um encaixe dos games em teorias externas a eles. A proposta, entretanto, não é esta, mas estudar os games como um novo tipo de produto midiático, cuja complexidade é equivalente a dos meios anteriores - que, por sua vez, são muito mais do que meras "tecnologias para contar estórias", como queria Aarseth (2004, p. 45). Um pressuposto fundamental deste texto é, portanto, que os games são produtos midiáticos e, como as poesias e os romances, os documentários e os filmes, os programas de entrevista e as novelas, têm muitos formatos, gêneros e funções - entre elas, também a de contar estórias. É igualmente relevante assinalar que a escolha de uma específica sucessão de formas expressivas para encaminhar a discussão não reflete crença na existência de uma continuidade - ou, menos ainda, de uma evolução - na história das mídias. O conjunto escolhido é resultado da revisão de literatura, e corresponde às mídias para as quais a ideia de suspensão de descrença foi aplicada com maior frequência. A literatura, o teatro, o cinema, a televisão e os games coexistem e se influenciam mutuamente e, sendo assim, o que sabemos sobre cada um deles pode ajudar a compreender os demais.

Finalmente, o artigo faz parte de um movimento de reaproximação entre a questão das representações espaciais, temática central de minhas pesquisas há mais de três décadas, e o estudo dos games, que também têm sido objeto de minha atenção desde a tese de doutorado, concluída em 1998. É interessante perceber que, na época, no Brasil, os artefatos digitais (entre eles, os games) só costumavam ser considerados temática pertinente para a Comunicação quando disponíveis pela internet. De lá para cá, as mudanças ocorridas na área em nosso país e a enorme popularização e diversificação do universo dos games viabilizaram o reconhecimento da pertinência dessa temática. Uma vez integrado ao paradigma científico vigente $^{3}$ (KUHN, 2000), o estudo dos games tem avançado rapidamente, como se verifica pela crescente presença do tema em publicações (livros e periódicos), em eventos e entre as dissertações e teses defendidas, sobretudo a partir de 2005.

2 Rigorosamente, trata-se de uma contenda que marcou o estudo de games entre a última década dos anos 90 e a primeira desta século, tendo como figuras proeminentes, por exemplo, entre os narratólogos, Brenda Laurel e Janet Murray e, entre os ludólogos, Espen Aarseth e Jesper Juul.

3 Thomas Khun define os paradigmas científicos como o conjunto de crenças e premissas hegemônico que, durante o período de sua vigência, determina não apenas os temas, mas também os problemas, os métodos e as soluções considerados legítimos por uma comunidade científica. 


\section{Suspensão voluntária de descrença}

A expressão suspensão de descrença foi cunhada pelo poeta inglês Samuel T. Coleridge no século XIX e, desde então, tem sido usada de forma extremamente livre. A primeira ocorrência da frase aparece no prefácio à segunda edição das Baladas Líricas (1802), a respeito da divisão de tarefas entre os dois co-autores, Coleridge e Wordsworth. De acordo com o texto, naquela obra, Wordsworth se ocupou das coisas cotidianas, com a intenção de "acordar a atenção da mente da letargia do hábito e direcioná-la para as belezas e maravilhas do mundo à nossa volta". Já Coleridge teria se dedicado às questões relativas às pessoas e personagens de natureza romântica "de modo a transferir de nossa natureza interior um interesse humano e uma aparência de verdade suficientes para prover a essas sombras da imaginação aquela momentânea suspensão voluntária de descrença que constitui a fé poética" (COLERIDGE, 2004, ênfase adicionada). Desde então, essa ideia foi repetida à exaustão, geralmente sem explicações sobre seu significado e sem a inclusão da palavra voluntária, que era importante para seu significado original. Na interpretação mais frequente, a suspensão de descrença é entendida como o abandono da capacidade crítica diante do apelo imersivo de um universo ficcional (por exemplo, em LAUREL, 1993; MURRAY, 1998). Entretanto, essa compreensão perde de vista o significado original da expressão para Coleridge ao deixar de levar em conta, por exemplo, a diferenciação entre descrença e ausência de crença, em que a primeira (descrença) é associada à ação voluntária, intelectual, racional, enquanto a ausência de crença é caracterizada pela ausência de poder e estagnação. Assim, para Coleridge, a suspensão voluntária de descrença não corresponderia a deixar-se levar pela ilusão e seria mais um acordo de cooperação que uma concessão (TOMKO, 2007).

\section{Imersão - da literatura aos games}

Um ponto em comum nas referências à suspensão de descrença é a ideia de imersão em um ambiente ficcional, de pleno envolvimento com o "universo espaçotemporal designado pela narrativa" (GENETTE 1988, p. 17). Hoje em dia essa ideia é mais frequentemente associada aos meios audiovisuais, porém não são incomuns as referências contemporâneas a estados de imersão deflagrados pela literatura. Um bom exemplo é a descrição, por Wertheim (1999), da experiência do leitor da Divina Comédia:

Um dos grandes apelos do épico de Dante é que seu mundo é tão arrebatadoramente real. Atravessando as valas fétidas do Malebolge ou escalando os terraços íngremes do Purgatório, você se sente como se estivesse realmente ali. Você quase pode sentir o fedor da sujeira do Inferno, ouvir o coral dos anjos no paraíso. Esta pode ser uma jornada da alma, mas poucas obras literárias evocam os sentidos físicos de forma tão poderosa. Ouve-se, vê-se, sente-se o cheiro do mundo que Dante retrata (p. 51). 
Essa citação é preciosa também para lembrar que, à primeira vista, a ideia de convidar o leitor para ingressar em um mundo imaginado parece afeita à dissociação cartesiana entre corpo e pensamento, que atravessa os estudos das narrativas e das mídias, inclusive das mídias digitais (FRAGOSO, 2010). Essa interpretação, entretanto, não é correta nem no que tange a leitura, que não é uma experiência descorporeificada, mas uma atividade multisensorial (MANGEN, 2008), nem em relação à obra de Coleridge, que já questionava o dualismo cartesiano (COLERIDGE, 2004, cap. VIII). Em seu trabalho, as referências mais próximas à ideia de descorporificação acontecem quando ele compara a suspensão de descrença ao sonho:

O poeta não nos pede que estejamos acordados e acreditemos, ele nos pede apenas que nos entreguemos a um sonho; e isso com os olhos abertos, e com a capacidade de julgamento oculta atrás das cortinas, pronta para nos acordar ao primeiro sinal de nossa vontade: e, nesse meio tempo, apenas, que não desacreditemos (COLERIDGE, 2004).

É também através de uma comparação com o sonho que Metz (1982) encaminha sua discussão sobre a imersão no cinema - e também ele destaca que a suspensão de descrença não corresponde propriamente ao sonho, mas ao sonho acordado (daydream) pois, enquanto o sonhador não sabe que está sonhando, o espectador do cinema sabe que está assistindo a um filme e apenas concorda em deixar de lado esse conhecimento para melhor se envolver com a narrativa. Para Metz, a viabilidade do estabelecimento desse regime psicológico singular, que ele denomina "capacidade ficcional", é uma habilidade desenvolvida a partir do convívio com a tradição aristotélica das artes em geral, mas que depende da disponibilidade de uma ambientação própria, que induz ao relaxamento do corpo e ao apagamento de seu entorno: a sala escura, o silêncio, a relativa imobilidade. Talvez mais importante do que tudo seja, entretanto, o acordo prévio de "portar-se como espectador" que o público estabelece com a instituição cinematográfica (METZ, 1982, pp. 116-119).

Os acordos de espectador que o público estabelece com o cinema e a televisão são bastante diferentes, com efeitos significativos sobre a suspensão de descrença. Entre os fatores mais proeminentes está a fragmentação da experiência televisiva - pela alternância entre os diferentes temas e gêneros ao longo da programação, pela ruptura interna de cada programa para intervalos comerciais ou, ainda, pela quebra das narrativas em episódios. Igualmente importantes são as condições de recepção que, tipicamente, no caso da televisão, não envolvem a imobilidade e o isolamento, como no cinema, mas o atravessamento pelos sons e imagens do cotidiano (MACHADO, 2000, p. 87). Além de assistir TV com as luzes ligadas, a maioria das pessoas o faz enquanto desempenha outras atividades: comer, cozinhar, falar ao telefone, conversar, etc. A tomar pela ênfase que Metz (1982) coloca sobre a continuidade e a necessidade da ambientação para a experiência imersiva, seria de esperar que a fragmentação e a interferência do ambiente 
doméstico inviabilizassem a suspensão de descrença na TV, ou, pelo menos, acarretassem um envolvimento menos intenso com a ficção televisiva do que aquele que se estabelece no cinema. Entretanto, o que se verifica não é isso: basta lembrar das muitas casas brasileiras que contam com um aparelho televisor na cozinha, no qual as pessoas acompanham seus programas preferidos enquanto jantam ou cozinham, muitas vezes emocionando-se até as lágrimas, mas sem deixar queimar as batatinhas ou errar o ponto do sal. Caracteriza-se assim uma situação televisiva (FRAGOSO, 2000), que é correlata ao estado fílmico de Metz, porém na qual a suspensão de descrença não está associada à continuidade da narrativa e ao apagamento do entorno, mas a uma elevada habilidade de abstrair as rupturas e de situar-se ao mesmo tempo dentro e fora da ficção. Esse novo patamar da "capacidade ficcional" atesta o refinamento do domínio dos telespectadores sobre a suspensão de descrença, que teria sido incrementado por décadas de convívio com o cinema e com a própria televisão.

Os games tornaram ainda mais complexas as condições para a suspensão de descrença, tanto devido à interatividade - entendida como a interação com a representação propriamente dita - quanto pelas possibilidades de interação social - que é a interação entre atores sociais mediada pela representação digital. Essas e outras características acentuaram a permeabilidade entre o espaço cotidiano e o espaço narrativo a tal ponto que, diante dos games, a imersão na situação televisiva chega a parecer uma conquista modesta. Entretanto, antes de tratar dessas especificidades dos games e o que elas implicam, é interessante abrir parênteses para revisitar algumas críticas às próprias ideias de imersão e suspensão de descrença.

\section{Criação e encenação de crença}

Em um subcapítulo de seu livro Hamlet on the Holodeck sugestivamente intitulado "a criação ativa da crença", Murray critica a ideia de suspensão voluntária da descrença, que considera demasiadamente passiva:

O prazer de entregar a mente a um mundo imaginário é frequentemente descrito, pela frase de Coleridge, como "a voluntária suspensão da descrença". Mas esta é uma formulação passiva demais mesmo para os meios tradicionais. Quando nós entramos um mundo ficcional, nós não apenas 'suspendemos' a capacidade crítica, nós também exercemos uma capacidade criativa (MURRAY, 1997, p. 110, ênfase adicionada).

De fato, a fruição de qualquer produto midiático é sempre um ato criativo. Por outro lado, essa crítica não faz jus a Coleridge, que não pensava a suspensão de descrença em termos da interrupção da capacidade crítica. É Murray quem concebe a imersão como uma sobrecarga de estímulos que obstruem a razão - o que fica explícito, por exemplo, quando, apesar de criticar as opiniões distópicas de Ray Bradbury, ela recorre a uma de 
suas obras ${ }^{4}$ como uma alegoria da imersão induzida pela TV, em que "as espectadoras da televisão estão hipnotizadas por uma ilusão tão intensa que impede a percepção de um perigo iminente" (MURRAY, 1997, p. 21). É apenas quando trata das narrativas mediadas por tecnologias digitais (cuja referência é também um exemplo ficcional, o holodeck ${ }^{5}$ que dá título a seu livro) que Murray demarca o caráter ativo de sua ideia de criação de crença. Nessas passagens, a autora destaca, inclusive, que o diferencial entre as mídias que ela denomina tradicionais e as narrativas em meios digitais residiria justamente na superação da passividade.

Outro clássico da literatura sobre o entretenimento digital que critica a expressão suspensão de descrença é Rules of Play (2004). Nesse livro, Salen e Zimmerman recuperam uma colocação de François Dominic Laramée, para quem "todas as formas de entretenimento buscam produzir suspensão de descrença, um estado em que a mente do jogador esquece que está sendo sujeitada a entretenimento e aceita o que percebe como se fosse a realidade" (SALEN e ZIMMERMAN, 2004, p. 450) Com essa citação como epígrafe, os autores encaminham sua discussão sobre o que denominam "falácia da imersão", definida como o pressuposto de que "o prazer da experiência midiática depende da capacidade de transportar o participante para uma realidade ilusória, simulada" (p. 450). A despeito do excessivo peso da associação entre essa ideia da imersão como uma falácia e um entendimento simplista da suspensão voluntária de descrença, é preciso reconhecer a perspicácia dos autores, que entendem que o envolvimento com os games envolve um estado de "dupla consciência em que o jogador está plenamente consciente da artificialidade da situação de jogo" (SALEN e ZIMMERMAN, 2004, p. 451, ênfase adicionada). Esse duplo estado de consciência é também referido por McGonical (2003). Ao contrário de Salen e Zimmerman, entretanto, McGonical não rejeita a ideia de suspensão de descrença e, inclusive, destaca a importância do reconhecimento de seu caráter voluntário em qualquer experiência midiática. Para tanto, retoma a crítica de Gunning (1998) às descrições da reação aterrorizada dos espectadores à exibição de Chegada de um Trem à Estação por Lumiére em 1895. Tendo constatado a ausência de registros históricos confiáveis sobre a veracidade desse acontecimento, Gunning colocou em cheque a ideia de uma audiência tão avassaladoramente ingênua e alertou para o perigo das manobras retóricas que permitiram que esse evento mítico passasse a ser tratado como evidência da passividade dos receptores diante dos meios audiovisuais (1998, p. 115).

A esse respeito, vale a pena revisitar também o trabalho de Mannoni sobre o teatro (1977), que serviu de referência para a obra citada de Metz (1982) e levanta hipóteses interessantes sobre os motivos para o poder de atração dessa ideia da existência da audiência ingênua. Para Mannoni, a imagem de um espectador simplório que acredita na representação responde a uma tensão entre a convicção de que o teatro deveria,

4 Fahrenheit 451, de 1953.

5 O holodeck é um dispositivo narrativo interativo e multisensorial da série de ficção Star Trek: Voyager, popular nos anos 1990. 
de fato, criar uma ilusão suficientemente perfeita para iludir o público e o fato de que isso não acontece. A natureza da ilusão teatral, diz o autor, não pode ser compreendida meramente em termos de crença, pois o papel simbólico do teatro-e, pode-se acrescentar, de toda narrativa - teria relação com a negação, no sentido Freudiano, e portanto sua fruição requer que "nunca seja, decerto, nossa ilusão, mas sempre - estranhamente, a de outro espectador, que não sabemos onde situar" (Mannoni, 1997, p.124).

McGonical (2003) responde à associação entre a ideia de suspensão voluntária de descrença e esse outro espectador, ingênuo, com a proposta de que a relação do jogador com o game estaria melhor caracterizada como uma encenação de crença do que como suspensão de descrença. Essa ideia difere da criação de crença de Murray (1998) - a cujo trabalho McGonical não chega a fazer referência - em sentidos importantes para contrapor alguns estigmas que têm sido associados aos jogos. Afinal, enquanto as acusações de alienação pelas mídias analógicas costumam vincular a passividade e a imersão, no caso dos games é justamente o envolvimento ativo do jogador que tem sido responsabilizado por uma suposta perda de noção dos limites entre o jogo e a realidade. Ao invés de criar crença, o que significaria que o jogador faz com que ele mesmo acredite no universo ficcional do game, a encenação de crença indica que o jogador apenas age como quem acredita. O duplo estado de consciência típico do jogo seria, então, caracterizado pelo fato de que o jogador sabe, o tempo todo, que o jogo não é a realidade, apenas faz de conta que pensa que é - o que é muito diferente de realmente acreditar que seja.

\section{Imersão e encenação de crença em games}

O principal diferencial das mídias digitais em relação às tecnologias midiáticas anteriores reside na interatividade, entendida como a interação com a representação (FRAGOSO, 2001). Essa noção converge com a ideia de agência, definida como a possibilidade de "experimentar um evento como o seu agente, como aquele que age dentro do evento e como o elemento em função do qual o próprio evento acontece" (MACHADO, 2002). No contexto dos games narrativos, a agência corresponde à possibilidade de interferir no desenvolvimento da estória (LAUREL, 1993; MURRAY, 1998) ou, mais especificamente, à obrigatoriedade de intervir, já que sem a ação do jogador os acontecimentos do mundo do jogo não se desenvolvem. Outras respostas à ausência de participação do jogador também são possíveis, por exemplo, reações específicas dos elementos do mundo ou dos NPCs ${ }^{6}$. Vários exemplos podem ser encontrados no variado e extenso universo dos games. Em uma escolha arbitrária, é possível mencionar Portal (Valve Corporation, 2007), em que o jogador controla um personagem que precisa resolver uma série de enigmas para atravessar um conjunto de salas. Em algumas situações nessas câmaras de teste, o jogador pode interromper sua atividade por quanto tempo quiser,

6 NPCs (Non Player Characters) são personagens cujas ações não são controladas pelo jogador. 
sem que nada se altere. Em outras, a inação leva ao fim do jogo. Tanto em um caso quanto em outro, o game exige que o jogador participe forma ativa e positiva na criação da ficção - sob risco de ser jogado para fora dela. Essa participação é necessariamente mediada por diversas camadas de representação, que complexificam as condições da encenação de crença, mesmo porque existe uma diferença ontológica entre o mundo do jogo e o mundo do jogador, que pode ser compreendida, de forma simplificada, pelo fato de que o mundo do jogador é o mundo físico, o mundo das coisas materiais (em seu sentido mais estrito), enquanto o mundo do jogo é um mundo imaginário. Entre outras coisas, isso implica que, embora o mundo do jogo faça parte do mundo do jogador, o jogador não faz parte do mundo do jogo: escolhendo arbitrariamente um outro jogo como exemplo, pode-se dizer que quem joga The Legend of Zelda (Nintendo, 1986) sabe da existência de uma princesa chamada Zelda que precisa ser libertada, mas, no mundo do jogo, que é o reino de Hyrule, nem Zelda nem seus inimigos sabem que existe um jogador cujos esforços estão por trás do eventual sucesso do resgate. Justamente porque sua existência é externa à do mundo do jogo, o jogador não pode influenciar os acontecimentos sem o auxílio de dispositivos que efetuem a passagem de uma instância para a outra, ou seja, que traduzam suas ações no mundo que ele habita para o mundo de Zelda. Essa tradução é realizada, evidentemente, pelas interfaces, tanto as de hardware (os controladores, telas e outros dispositivos físicos) quanto as de software (as representações internas e externas ao mundo do jogo). Como em toda tradução, também nesse processo os dois tipos de interfaces acrescentam incongruências e causam rupturas que afetam a relação entre o jogador e o jogo - e, com ela, as condições de encenação de crença.
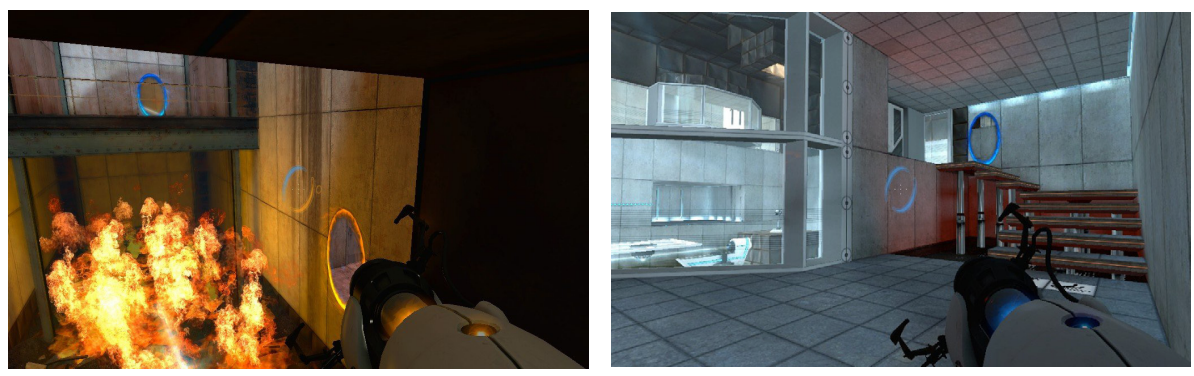

Fig 1. Duas situações no jogo Portal (Valve Corporation, 2007). À esquerda,o jogador precisa agir ou será jogado no fogo; à direita nada acontece até que o jogador aja. Fonte: Strategy Wiki (http://strategywiki.org)

Em princípio, seria de se esperar que as incongruências que as interfaces introduzem no mundo do jogo comprometessem a experiência imersiva (DOUGLAS e HARGADON, 2004). Estudos empíricos como os realizados por Llanos \& Jørgensen (2011), entretanto, apontam em outra direção e indicam que desconexões entre os elementos de interface e a coerência interna do mundo do jogo não comprometem o envolvimento entre o jogador 
e o game. O mesmo se estende às disparidades entre as ações requeridas pelas interfaces de hardware e seu efeito sobre o mundo do jogo, que costumam ser ainda mais acentuadas: empurra-se uma alavanca do controle do console para a frente para que o personagem ande ou aperta-se a barra de espaços do teclado do computador para que ele pule, por exemplo. A diferença entre os acontecimentos nos dois domínios - o mundo do jogador (que aperta o botão) e o mundo do jogo (em que o personagem pula) - deveria chamar a atenção do jogador para a exterioridade de sua posição em relação ao mundo do jogo, interrompendo o envolvimento com a narrativa. Revela-se, aí, a incoerência de descrever a experiência dos games como "criação de crença", como propôs Murray (1998). Seria mais pertinente falar em "suspensão voluntária de descrença" por parte do jogador, cujo caráter deliberado converge com a formulação original de Coleridge (2004) e desautoriza as relações com a ideia de audiência ingênua, criticada anteriormente neste texto. Isso porque o que se vê, na prática, não é a perda de referência do entorno imediato em função de uma sobrecarga de estímulos vinda da representação (MURRAY, 1998), mas uma refinada e hábil conciliação da atenção aos controles e aos acontecimentos do mundo do jogo, sem prejuízo da experiência imersiva. Essa coordenação dos controles - e outros elementos do entorno no mundo físico - com os acontecimentos no mundo do jogo. Nesse sentido, convergem as ideias de "capacidade ficcional" (METZ, 1982), anteriormente mencionada em relação à recepção televisiva, e do "duplo estado de consciência" que, para Salen e Zimmerman (2004), caracterizaria a situação de jogo. É possível dizer, então, que a "encenação de crença" (McGONICAL, 2003) consiste na conjugação da consciência que o jogador tem de que está jogando - sem a qual ele não seria capaz de utilizar os recursos das interfaces de software e de hardware - com sua opção de desconsiderar as disparidades que essa situação impõe sobre a representação do mundo do jogo. Essa habilidade aparentemente complexa se revela bastante mais simples quando relacionadas à infância. Todos nós, quando crianças, brincamos de fingir que acreditávamos em algo que era parte de um jogo: por exemplo, corríamos desesperados pelo pátio gritando por socorro enquanto um colega nos perseguia grunhindo como um monstro, sem que isso significasse que tínhamos esquecido, sequer por um momento, que era apenas alguém conhecido, fazendo as vezes de monstro para brincar conosco. Diversões desse tipo não constituem mentiras, nem o prazer que delas decorre é visto como perversidade: trata-se apenas de contar com a concordância de cada um em fazer a sua parte para garantir a continuidade do jogo, entrando ativamente (mas sem perder o discernimento) no faz-deconta. Assim, a relação entre o jogador e o game constitui um acordo de jogador, análogo aos acordos de espectador estabelecidos com o cinema (METZ, 1982) e a TV (FRAGOSO, 2000), em que o participante encena sua crença nos acontecimentos do jogo.

\section{Conclusão}

Os games evidenciam algumas peculiaridades do envolvimento com as narrativas midiáticas que desafiam as ideias de imersão e de uma audiência ingênua, que acreditaria 
na representação a ponto de confundi-la com a realidade. Alguns autores já haviam percebido que, ao contrário dessa suposta ingenuidade, o espectador do teatro, do cinema e da televisão sempre demonstrou habilidade para relacionar-se ao mesmo tempo com os universos ficcionais narrativos e com os acontecimentos do mundo ao seu redor. A interatividade que caracteriza os produtos midiáticos digitais destacou e intensificou essa capacidade, já que a interação com esse tipo de representação implica a possibilidade ou, mais propriamente, a necessidadede interferência. No caso dos jogos, essa ação sobre os acontecimentos se alia às disparidades entre os movimentos realizados nas interfaces de hardware e seus efeitos sobre as interfaces de software, compondo uma situação que desafia inclusive algumas ideias desenvolvidas para caracterizar justamente a experiência específica dos meios interativos. É o caso da noção de "criação de crença" (MURRAY, 1998), que se revela menos adequada que "suspensão voluntária de descrença" - desde que se tenha o cuidado de reconhecer o caráter deliberado enfatizado em sua origem (COLERGIDGE, 2004). A experiência dos games indica que a habilidade dos jogadores com os games é melhor caracterizada como "duplo estado de consciência" (SALEN e ZIMMERMAN, 2004), pois o jogador, consciente de que está jogando, desconsidera deliberadamente as disparidades entre as ações que realiza com seu corpo e seus efeitos na representação. Trata-se, nesse sentido, de "encenação de crença" (McGONICAL, 2003), equivalente a um novo patamar de capacidade ficcional. Trata-se de um acordo de jogador, correlato ao acordo de "portar-se como espectador" anteriormente identificado na relação entre o público eo cinema (METZ, 1982) e a televisão (FRAGOSO, 2000), que se caracteriza justamente por essa atuação em múltiplas instâncias, de realidade e representação, cujo caráter explícito é um dos principais diferenciais dos games.

Suely Fragoso é professora doutora no Programa de PósGraduação em Comunicação e Informação e no Programa de Pós-Graduação em Design da UFRGS.

suelyfragoso@ufrgs.br

\section{Referências}

AARSETH, Espen. Genre Trouble: narrativism and the art of simulation. In: WARDRIP-FRUIN, Noah e HARRIGAN, Pat (Orgs) First Person: new media as story, performance and game. Cambridge: MIT Press, 2004, pp. 45-55.

BOLTER, Jay D. e GRUSIN, Richard. Remediation: understanding new media. Cambridge: MIT Press, 1999.

COLERIDGE, Samuel T. Biographia Literaria. EBook \#6081, Project Gutenberg, Release date Julho de 2004, Última atualização Janeiro de 2013. Disponível em http://www.gutenberg.org/ebooks/6081 [05/02/2013] 
DOUGLAS, J. Yellowlees e HARGADON, Andrew. The Pleasures of Immersion and Interaction: schemas, scripts and the fifth business. In. WARDRIP-FRUIN, Noah e HARRIGAN, Pat (Orgs) First Person: new media as story, performance and game. Cambridge: MIT Press, 2004, pp. 192-206.

FRAGOSO, S. Situação TV. In. MALDONADO, E. et al. (Orgs) Mídias e Processos Socioculturais. São Leopoldo: Unisinos, 2000, pp. 101-114. Disponível em http://www.academia.edu/2537713/ Situacao_TV [20/10/2013]

FRAGOSO, S. de interações e interatividade. Revista Fronteiras - estudos midiáticos 3 (1), 2001, pp. 83-95. Disponível em http://www.academia.edu/247813/de_interacoes_e_interatividade [20/10/2013]

FRAGOSO, S. Cunctus Ergo Sum: crítica à compreensão cartesiana de sujeito nos estudos da cibercultura. In. TRIVINHO, E. e dos REIS, A. P. (Orgs) A cibercultura em transformação: poder, liberdade e sociabilidade em tempos de compartilhamento, nomadismo e mutação de direitos. São Paulo: ABCiber; Instituto Itaú Cultural, 2010. Disponível em http://www.abciber.com/publicacoes/ livro2 [20/10/2013]

GENETTE, Gérard. Narrative discourse revisited. New York: Cornell University Press, 1988

GROMALA, Diane. Response to Stuart Mouthrop. In. WARDRIP-FRUIN, Noah e HARRIGAN, Pat (Orgs) First Person: new media as story, performance and game. Cambridge: MIT Press, 2004, pp. 56-60.

GUNNING, Tom. An Aesthetic of Astonishment: Early Film and the (In)Credulous Specator. In. BAUDY, Leo and COhen, Marshall (Orgs) Film Theory and Criticism. New York: Oxford University Press, 1998, pp. 114-133

KUHN, Thomas. A Estrutura das Revoluções Científicas. São Paulo: Perspectiva, 2000.

LAUREL, Brenda. Computer as Theatre. Reading :Addison-Wesley, 1993.

LLANOS, Stein C. e JØRGENSEN, Kristine. Do Players Prefer Integrated User Interfaces? A Qualitative Study of Game UI Design Issues. Proceedings of DiGRA 2011 Conference: Think Design Play, Utrecht, Holanda, 14-17 de setembro de 2011. Disponível online em http://www.digra.org/dl [05/02/2013]

MACHADO, Arlindo. A Televisão Levada a Sério. São Paulo: SENAC, 2000.

MACHADO, Arlindo. Regimes de Imersão e Modos de Agenciamento. Anais do XXV Intercom, Salvador, 1-5 de setembro de 2002. Disponível online em http://comunidadesvirtuais.pro.br/hipertexto/ home/Imersao\%20e\%20Agenciamento\%20-\%20Machadotexto5.pdf [05/02/2013]

MANGEN, Anne. Hypertext Fiction Reading: haptics and immersion. Journal of Research in Reading 31(4), 2008, pp. 404-419.

MANNONI, Octave. La Outra Escena: claves de lo imaginario. Buenos Aires: Amorrortu Editores, 1997.

McGONICAL, Jane. A Real Little Game: the performance of belief in pervasive play. . Proceedings of DiGRA 2003 Conference: Level Up, novembro de 2003. Disponível online em http://janemcgonigal. files.wordpress.com/2010/12/mcgonigal-a-real-little-game-digra-2003.pdf [05/02/2013]

METZ, Christian. The Imaginary Signifier: psychoanalysis and the cinema. Bloomington: Indiana University Press, 1982.

MURRAY, Janet. Hamlet on the Holodeck: the future of narrative in cyberspace. Cambridge: MIT Press, 1998

O'HARA, Kenton; GRIAN, Hazel e WILLIAMS, John. Participation, collaboration and spectatorship in an alternate reality game. Proceedings of the $\mathbf{2 0}^{\text {th }}$ Australasian Conference on ComputerHuman Interaction: Designing for Habitus and Habitat - OZCHI'08, pp. 130-139. DOI 10.1145/1517744.1517787 [05/02/2013] 
OLIVEIRA, Thaiane e ANDRADE, Luiz Adolfo de . Um jogo de realidades e ficcionalidades. Ciberlegenda 22, 2010. Disponível online em http://www.proppi.uff.br/ciberlegenda/um-jogo-derealidades-e-ficcionalidades [05/02/2013]

SALEN, Katie e ZIMMERMAN Eric. Rules of Play: game design fundamentals Cambridge: MIT Press, 2004.

TOMKO, Michael. Politics, Performance, and Coleridge's "Suspension of Disbelief" Victorian Studies 49 (2), 2007, pp. 241-249. Disponível online em https://muse.jhu.edu/journals/victorian_studies/toc/ vic49.2.html [05/02/2013]

WERTHEIM, Margareth. The Pearly Gates of Cyberspace: a history of space from Dante to the Internet. New York, W. W. Norton \& Company, 1999.

Artigo recebido em setembro e aprovado em novembro de 2013. 